\title{
Costs of tuberculosis disease in the European Union: a systematic analysis and cost calculation
}

\author{
Roland Diel ${ }^{1}$, Joris Vandeputte ${ }^{2}$, Gerard de Vries ${ }^{3,4}$, Jonathan Stillo ${ }^{5}$, \\ Maryse Wanlin ${ }^{6}$ and Albert Nienhaus ${ }^{7}$
}

\author{
Affiliations: \\ ${ }^{1}$ Institute for Epidemiology, University Medical Hospital Schleswig-Holstein, Airway Research Center North, \\ Member of the German Center for Lung Research (DZL), Kiel, and \\ ${ }^{7}$ Institute for Health Service Research in Dermatology and Nursing, University Medical Center Hamburg- \\ Eppendorf, Hamburg, Germany. \\ ${ }^{2}$ Trivarop SPRL, Colfontaine, and \\ ${ }^{6}$ Belgian Lung and Tuberculosis Association, Brussels, Belgium. \\ ${ }^{3}$ Regional Office The Netherlands \& Europe, KNCV Tuberculosis Foundation, The Hague, and \\ ${ }^{4}$ National Institute for Public Health and the Environment, Bilthoven, The Netherlands. \\ ${ }^{5}$ City University of New York Graduate Center, New York, NY, USA.
}

\section{Correspondence:}

R. Diel, Institute for Epidemiology, University Medical Hospital Schleswig-Holstein, Niemannsweg 11, 24105 Kiel, Germany.

E-mail: roland.dieldepi.uni-kiel.de

ABSTRACT Without better vaccines it is unlikely that tuberculosis (TB) will ever be eliminated. An investment of $\sim € 560$ million is considered necessary to develop a new, effective vaccine in the European Union (EU). However, less is known about the costs of TB disease in the EU. We performed a systematic review of literature and institutional websites addressing the $27 \mathrm{EU}$ members to summarise cost data. We searched MEDLINE, EMBASE and Cochrane bibliographies for relevant articles.

Combining direct and indirect costs, we arrived at an average per-TB case costs in the original EU-15 states plus Cyprus, Malta and Slovenia of $€ 10282$ for drug-susceptible TB, $€ 57213$ for multidrug resistant (MDR)-TB and $€ 170744$ for extensively drug resistant (XDR)-TB. In the remaining new EU states, costs amounted to $€ 3427$ for drug-susceptible TB and $€ 24166$ for MDR-TB/XDR-TB. For the 70340 susceptible TB cases, 1488 MDR-TB and 136 XDR-TB cases notified in 2011 costs of $€ 536890315$ accumulated in 2012. In the same year, the 103104 disability-adjusted life years caused by these cases, when stated in monetary terms, amounted to a total of $€ 5361408000$.

Thus, the resulting economic burden of $\mathrm{TB}$ in the EU clearly outweighs the cost of investing in more efficient vaccines against TB.

@ERSpublications

The economic burden of tuberculosis in the EU outweights the cost of investing in more efficient vaccines against tuberculosis http://ow.ly/qXW4s

This article has supplementary material available from www.erj.ersjournals.com

A press release for this article is available from www.erj.ersjournals.com/site/misc/presspack.xhtml

Received: May 072013 | Accepted after revision: July 082013 | First published online: Aug 152013

Conflict of interest: None declared.

Copyright @ERS 2014 


\section{Introduction}

Although vaccination with bacille Calmette-Guérin (BCG), the only available vaccine against tuberculosis (TB), has been shown to decrease the risk of severe forms of TB in young children (disseminated TB and TB meningitis) [1], it is ineffective in preventing infectious pulmonary TB, which occurs mainly in adults and remains the primary source of TB transmission. Currently, 12 vaccines have been taken into phase I or II clinical trials, with the aim of replacing the present BCG vaccine or at enhancing immunity induced by BCG $[2,3]$, and with the hope of licensing at least one new vaccine by 2018 [4].

An investment of $\sim € 560$ million is considered necessary to achieve this result in the European Union (EU) [5]. As part of its efforts for funding, the Tuberculosis Vaccine Initiative (TBVI) has proposed an investment model to close the financial gap and speed up the development of those new TB vaccines [6]. The economic calculation that follows shows how the annual cost of TB in the EU clearly outweighs the total cost of developing new vaccines.

Confusion may arise as to the definition of the region when looking at the cost of TB in Europe. A much used estimation of TB-related costs in Europe, the European Academies Science Advisory Council study [7], comes from the European Lung White Book, which placed these in 2003 at $€ 2.1$ billion in the European region as defined by the World Health Organization (WHO), i.e. comprising 53 member states including the EU, EU-associated and former Soviet Union (FSU) countries [8]. However, some details of that cost calculation have not been provided and thus it is challenging to provide a more explicit, reasonable cost calculation of TB disease focusing on the current 27 member states of the EU (EU-27).

Numerous publications stress the dramatic increase of multidrug-resistant (MDR) and extensively drugresistant (XDR) TB in the world $[9,10]$. According to estimates by the WHO, of the total 8.7 million new cases in 2011 an estimated 3.7\% had MDR-TB [11], defined as resistance to at least the two most powerful first-line anti-TB drugs, isoniazid and rifampicin, and $\sim 58000$ cases involved XDR-TB, defined as resistance to any fluoroquinolone and at least one of the three injectable anti-TB drugs (amikacin, capreomycin or kanamycin) in addition to MDR.

Of the 22 countries considered "MDR-TB high burden", 15 are in the WHO Europe region [12]. In 2011 the number of cases tested for MDR-TB in Europe was 84140 , of which $68 \%$ delivered a positive bacteriological result [13].

The highest rates of MDR-TB, up to $26 \%$ among new cases and up to $65 \%$ among previously treated cases, are seen in the countries of the FSU $[14,15]$, which together had an estimated 31000 cases in total in $2010[16]$.

According to a recent document of the WHO Regional Office for Europe [17] the total number of notified XDR-TB patients in the WHO European region almost tripled, from 132 in 2008 to 344 in 2009.

For 2011, the European Centre for Disease Prevention and Control (ECDC) and WHO Regional Office for Europe surveillance report [18] mentions 1518 MDR-TB cases and 136 XDR-TB cases. This confirms that drug-resistant $\mathrm{TB}$ is an important problem, especially because it is well known to be associated with a relatively low treatment success rate $[19,20]$ and, as shown in our calculations later on, a significant increase in treatment cost. Accordingly, in every economic analysis the increasing cost of MDR-TB has to be included according to its proportion among all TB cases arising in the EU.

The historical summary of the Wolfheze workshops and their consensus documents with recommendations on $\mathrm{TB}$ control activities in the EU [21] highlights the ultimate target of TB elimination, defined as a TB incidence of less than one case per million population [22]. As it must be recognised, following current trends, Europe is unlikely to achieve elimination of the disease by the target date of 2050 [23, 24], we urgently need new vaccines, as well as improved diagnostics $[25,26]$ and new drugs [27-29]. With respect to economic considerations, the aim of the present study was to evaluate the costs associated with $\mathrm{TB}$ disease in order to determine whether they outweigh the investment needed to generate a new vaccine.

\section{Methods}

\section{Calculating direct and indirect costs}

First, we performed a systematic literature review, followed by the extraction of direct as well as indirect costs of TB (fig. 1). Direct costs include costs for the medical treatment of TB (medication, laboratory work, hospitalisation and outpatient visits) and indirect costs represent productivity loss because of TB-induced sick days taken off work.

From this we gathered information on the following cost components for drug-susceptible TB, MDR-TB and XDR-TB: 1) duration of hospitalisation and inpatient cost per day; 2) outpatient cost; 3) cost of medication; 4) cost due to loss of productivity; and 5) year in which the costs were assessed or collected. 


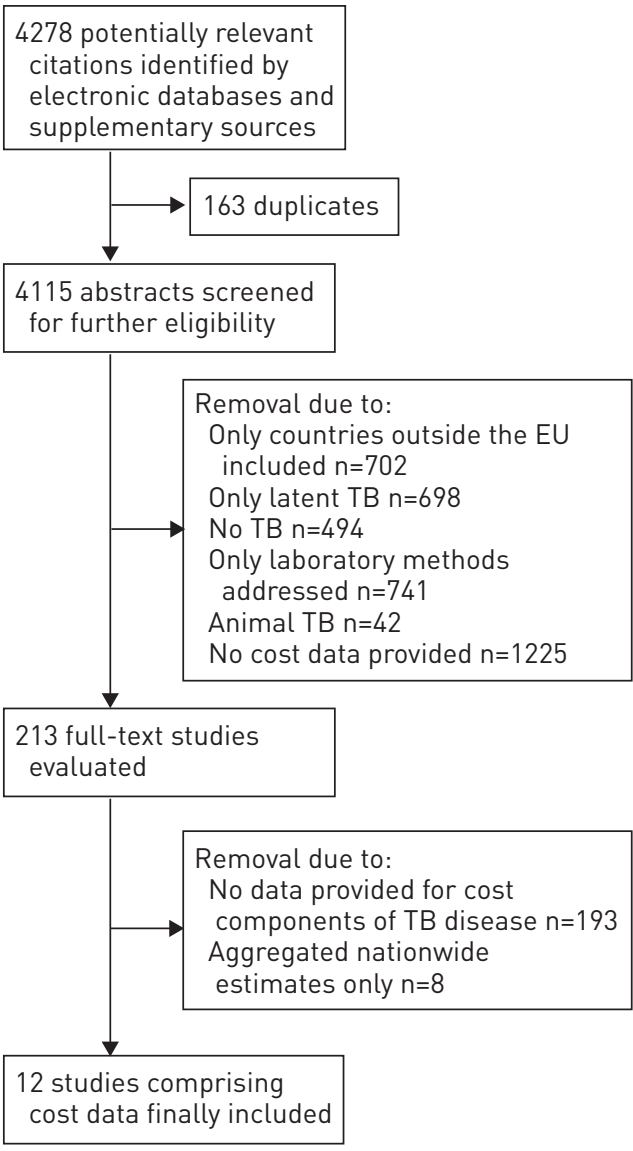

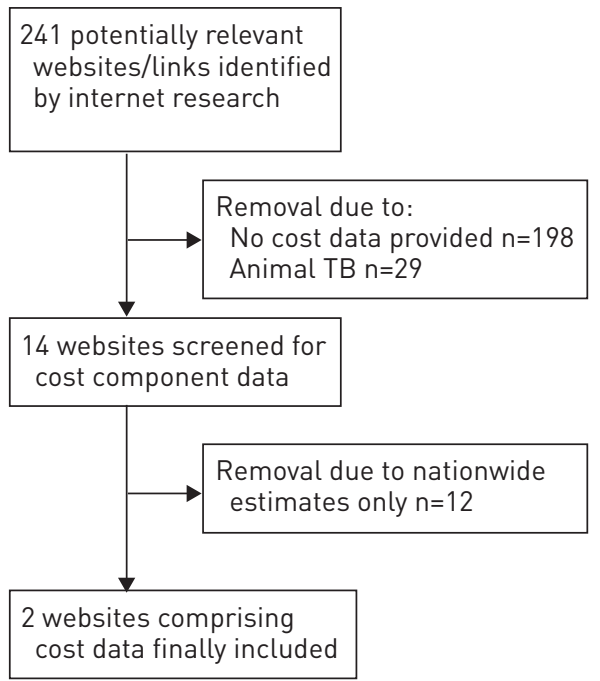

2 websites comprising

ost data finally included

If there was more than one cost calculation for a country the most current version was chosen in the review. It was the aim of our study to show current TB costs, so the price year of this study was 2012 . Consequently, all costs arisen in different EU countries and years were adjusted to 2012 values using the Harmonised Index of Consumer Prices for the Euro area countries [30] and the results were summarised.

Costs of public health surveillance, especially costs of contact tracing, screening risk groups, preventive treatment of persons latently infected by Mycobacterium tuberculosis and the activities of national reference laboratories and institutes were beyond the scope of this analysis.

We searched MEDLINE, EMBASE, the Health Economic Evaluations Database, Centre for Reviews and Dissemination/National Health Service Economic Evaluation Database, the Cost-Effectiveness Analysis Registry, the European Network of Health Economic Evaluation Databases and the Cochrane Central Register of Controlled Trials (CENTRAL) (Cochrane Library 2013, issue 3, through March 15, 2013) for studies published using the following search terms in different combinations: "tuberculosis" OR "TB disease" OR "MDR-TB” OR “drug resistant TB" OR “drug resistant tuberculosis" OR "multidrug resistant TB" OR "multidrug resistant tuberculosis" AND "cost" OR "cost-effectiveness" OR "economic" OR "burden".

No restrictions were made with respect to language, study design or data collection (prospective or retrospective). Secondary references cited by the studies and review articles retrieved from the databases were reviewed. In addition, the search terms were translated into the respective languages of all $27 \mathrm{EU}$ member states for web research using internet search services provided by Google and Yahoo in order to receive results from country-specific governmental or regional papers from the respective national statistical offices and authorities.

\section{Calculation of disability-adjusted life years and conversion to monetary terms}

Disability-adjusted life years (DALYs) represent the loss equivalent to 1 year of full health due to a specific disease, in this case TB. In brief, they are the sum of life years lost (YLL) due to premature mortality, i.e. the number of deaths due to TB multiplied by the standard life expectancy at the age at which death occurs, and 
of the years lived with the disability (YLD), the latter gained by multiplying incident TB cases by treatment duration and disability weight for the condition: DALY $=$ YLL+YLD.

The basic formula for calculation of YLL and YLD on a population basis are as follows: YLL $=[\mathrm{n} / \mathrm{r}]$ $\left(1-1-e^{-r L}\right)$, where $\mathrm{n}$ is the number of deaths, $\mathrm{L}$ is the life expectancy at age of death (years) and $\mathrm{r}$ is the discount rate; and $\mathrm{YLD}=\left[\mathrm{I} \times \mathrm{DW} \times \mathrm{L}\left(1-\mathrm{e}^{-\mathrm{rL}}\right)\right] / \mathrm{r}$, where $\mathrm{I}$ is the number of incident cases, DW is the disability weight and $\mathrm{L}$ is the duration of disability (years).

For practical purposes we calculated the difference between life expectancy and average age at death from $\mathrm{TB}$, summed across the EU-27 population and incorporated a $3 \%$ discount rate as well as a non-uniform age weighting (full equations are shown in the online supplementary material) [31]. In line with the Global Burden of Disease (GDB) study [32] we used an average disability weight for TB disease of 0.271. YLDs were calculated separately for drug-susceptible TB ( $\mathrm{L}=0.5$ years) and MDR-TB ( $\mathrm{L}=2$ years).

Finally, the resulting DALYs were multiplied by the long-established estimate of the European Commission of $€ 52000$ as value of 1 life-year lost (VOLY) [33], derived from citizens' responses to willingness-to-pay questionnaires on the topic of air pollution mortality, which remains unadjusted in consideration of the fact that the TB burden weighs more heavily on the poorer EU member states than it does on the former EU core members [34].

\section{Results}

Direct costs

In the selection process 4278 citations and 241 websites were identified, of which only 12 scientific articles [35-46] and two websites $[47,48]$ were eligible for final inclusion, as they contained specific information on at least one of the cost components as listed above. To take into consideration the gaps in gross domestic product (GDP) per capita between the 27 present EU member countries, we presented separately the results for the EU-15 states (member countries of the EU prior to the accession of 12 candidate countries on May 1, 2004 comprising the following 15 countries: Austria, Belgium, Denmark, Finland, France, Germany, Greece, Ireland, Italy, Luxembourg, Netherlands, Portugal, Spain, Sweden and the UK) and the other 12 countries that have since joined (table 1 shows figures of total treatment costs and table 2 shows the key features of all 12 studies included in our review).

Total costs of TB treatment for drug-susceptible and/or MDR-/XDR-TB could be obtained from the following countries.

UK

Aggregated governmental National Health Service data were available for the UK, in which a partitioning between hospital inpatients and outpatient visits was not provided, nor was cost of medication separately documented [47]. The total direct cost of treatment of a "normal" case of TB has been calculated to be around $\mathfrak{E} 5000$ in 2009 (equivalent to $€ 5864$ ) and cost of treatment of a drug-resistant case between $\mathfrak{E} 50000$ and $\mathfrak{E} 70000$ or $>\mathfrak{E} 70000$ per patient (equivalent to $€ 58624$ and $€ 82096$, respectively). This estimate is less

\section{TABLE 1 Countries for which total direct (treatment) costs of tuberculosis (TB) are available}

Costs per case $€$ adjusted to 2012

\begin{tabular}{|c|c|c|c|}
\hline & Drug-susceptible TB & MDR-TB & XDR-TB \\
\hline \multicolumn{4}{|c|}{ EU-15 member states } \\
\hline France & 5691 & NA & NA \\
\hline Germany & 7751 & 55003 & 188466 \\
\hline UK & 6234 & 62343 & NA \\
\hline Netherlands & 8340 & 46990 & 148136 \\
\hline Italy & 9294 & NA & NA \\
\hline Finland & 8242 & NA & NA \\
\hline Spain & 9384 & NA & NA \\
\hline Mean value & 7848 & 54779 & 168310 \\
\hline \multicolumn{4}{|c|}{ New EU members } \\
\hline Estonia & 2616 & 23355 & 23355 \\
\hline
\end{tabular}

MDR: multidrug resistant; XDR: extensively drug resistant; EU: European Union; EU-15: 15 original member states of the EU; NA: not available. 


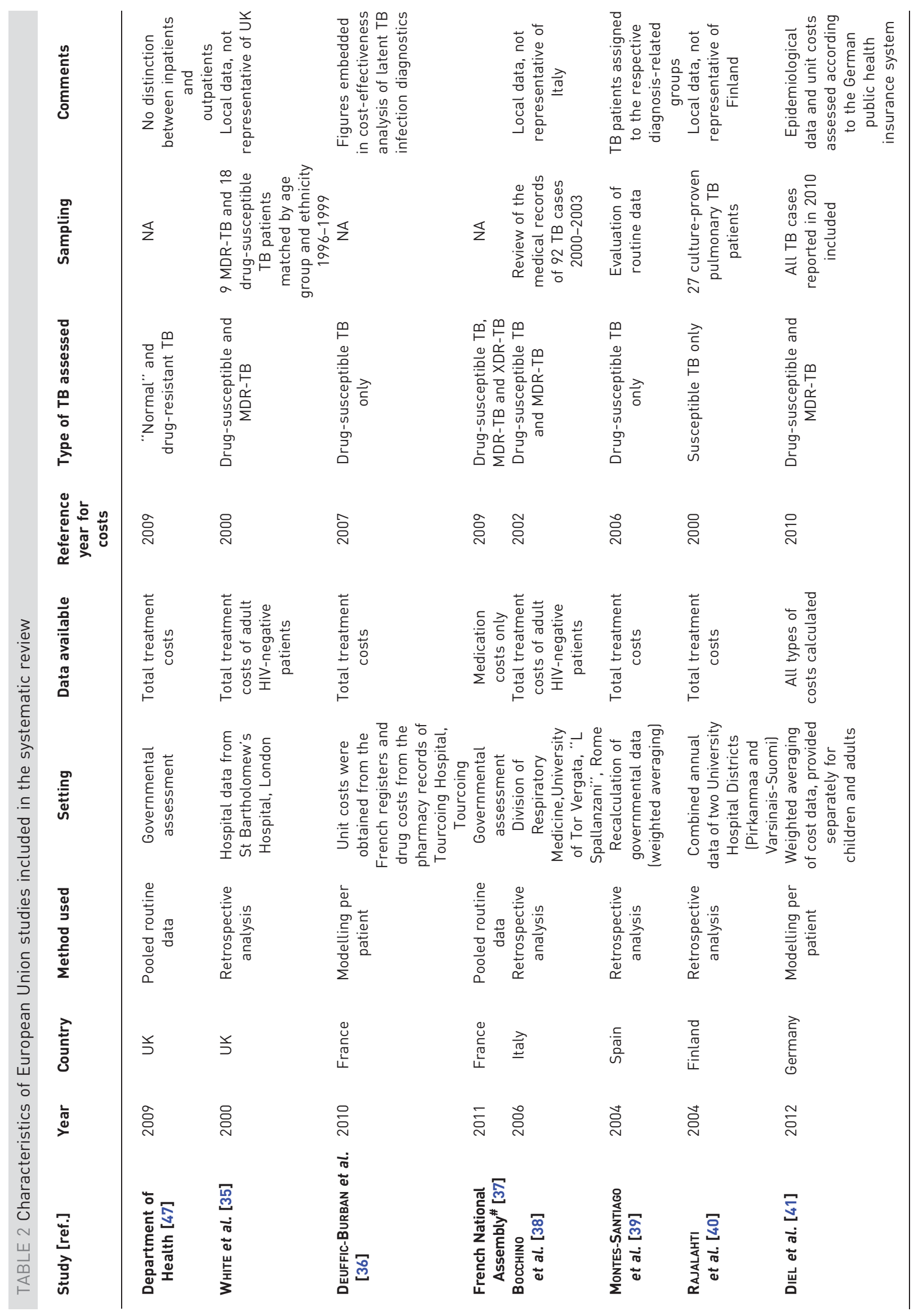




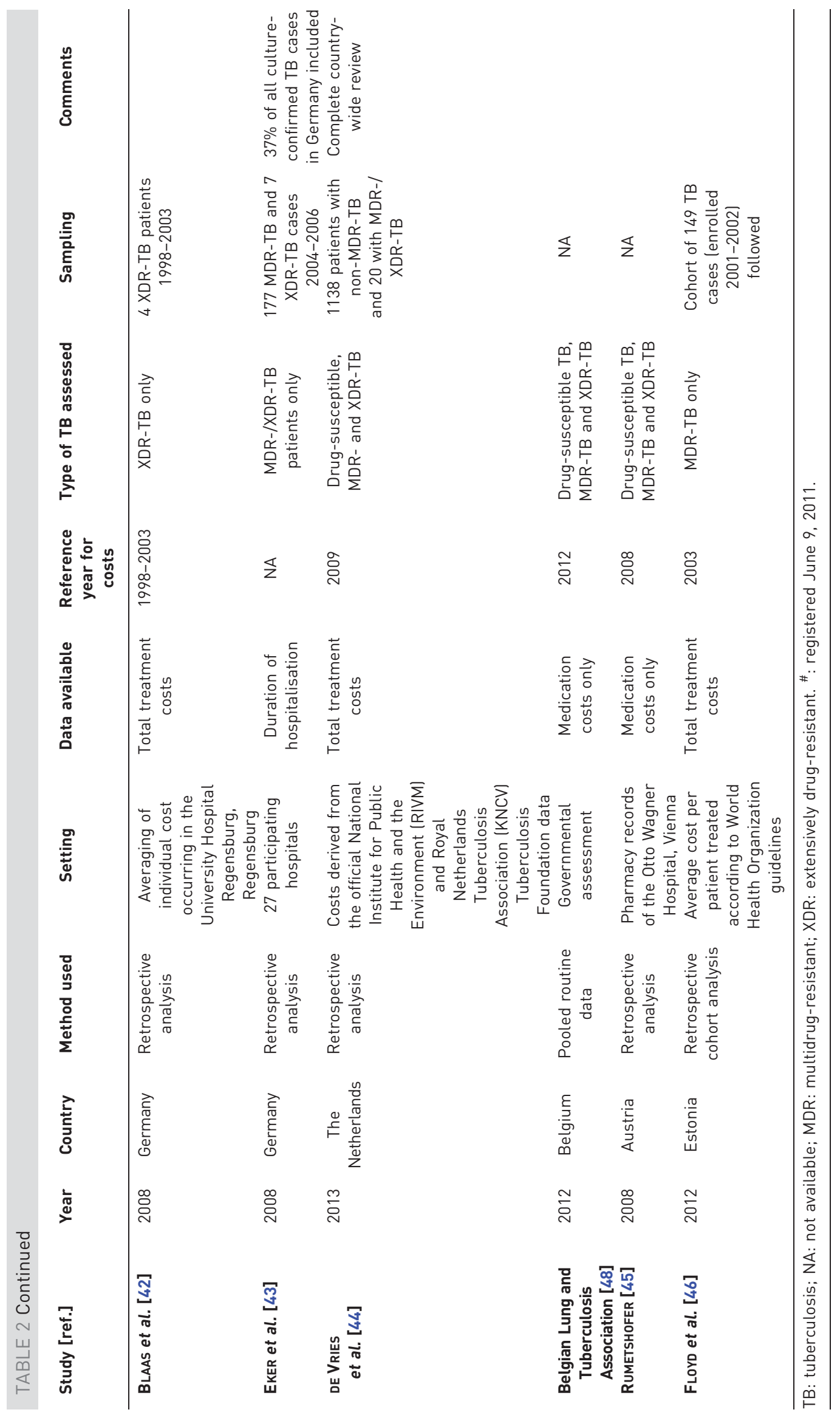


than assessed in previous calculations by WHITE et al. [35], presenting costs of $\mathfrak{E} 6040$ for a drug-susceptible

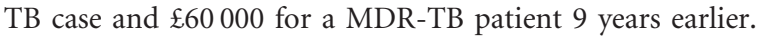

France

In France the direct cost for a drug-susceptible TB case have been calculated at $€ 5231.81$ for the year 2007 [36], including medication costs of $€ 268.20$.

The cost figure for medication only is in line with the governmental estimation of medication costs [37], which is $€ 250-450$ for 6 months of short-course therapy. In addition, for the year 2009, a cost range of $€ 27330-44235$ is shown for treatment of MDR-TB and $€ 46614$ of XDR-TB. However, these figures only refer to a duration of therapy of 12 months and, therefore, drastically underestimate the costs of a course of therapy as required by the previous [49] and current WHO guidelines [50]. These propose a minimum treatment duration of 18 and 20 months, respectively, after culture conversion for MDR-TB patients, i.e. usually a total of 24 months.

Italy

Bocchino et al. [38] investigated the treatment costs of TB taking into account all "fixed" expenses ( $€ 200.45$ per day for hospitalisation and $€ 50.12$ per day for any outpatient visit) and by adding the cost of drugs, tests and procedures for each case. The resulting annual costs arising in 2002 were a median (interquartile range (IQR)) of $€ 13413$ (€7364-20 194), but these costs also included 19\% MDR-TB cases. Thus, the value of the lowest quartile, representing only a quarter of the cost data, i.e. $€ 7364$, was chosen as the cost of treating drug-susceptible TB.

\section{Spain}

For Spain, the cost of hospitalisation and the total TB cost can be extrapolated from the study by MONTESSANTIAGO et al. [39], who calculated an amount of $€ 8175.33$, with $77 \%$ ( $€ 6279.31$ ) for hospitalisation costs in 2006.

\section{Finland}

Recalculated from the detailed unit costs given for 2000, the mean costs for a 6-month treatment, which comprised of inpatient stays of only 14 days, amounted to $€ 6673.10$ per drug-susceptible TB case [40].

\section{Germany}

The most recent data for the direct costs for Germany, calculated by Diel et al. [41], presented combined weighted inpatient/outpatient costs of $€ 7363.99$ per patient for drug-susceptible TB and $€ 52259$ per patient for MDR-TB, with an average duration of hospitalisation of 30 days for drug-susceptible cases and 86 days for MDR-TB cases. The costs for XDR-TB patients were not included in this cost analysis, but according to BLAAS et al. [42], in 2004-2006 the costs of treating XDR-TB patients in Germany amounted to more than $€ 170000$ per patient. As assessed by another German survey, the mean \pm SD treatment duration of XDR-TB cases as inpatients was $202 \pm 130$ days [43].

\section{The Netherlands}

In a recent retrospective analysis based on 1138 patients with non-MDR-TB and 20 with MDR-TB, DE VRIES et al. [44] calculated the total cost per patient. Costs due to drug-susceptible TB amounted to $€ 7854$, those due to MDR-TB to $€ 44250$ and those due to XDR-TB to $€ 139500$ [44].

Cost data for TB medication, but no figures for additional inpatient or outpatient costs, were available for the following two countries.

\section{Belgium}

According to the Belgian Lung and Tuberculosis Association, the cost of medication per TB case for 2012 ranges from $€ 368$ for a drug-susceptible TB case ( 6 months) to $€ 14307-41229$ for a MDR-TB case (1824 months) and to $€ 67067$ for an XDR-TB case (24 months) [48].

\section{Austria}

For 2008 there is an estimate of medication costs amounting to $€ 277.50$ for drug-susceptible TB and $€ 22291$ for MDR-TB in 2008 [45].

To estimate the TB patient costs of countries for which total cost data are not available we used for the average of the aforementioned costs for susceptible TB. Thus, the assumed average direct costs (after adjusting for 2012) are €7848 for Austria, Belgium, Denmark, Ireland, Greece, Luxemburg, Portugal and 
Sweden (table 1). An identical approach with respect to MDR-TB/XDR-TB results in average costs of $€ 54779$ and $€ 168310$, respectively.

\section{Countries where total costs were not available}

Estonia

In a recent publication by FLOYD et al. [46], in Estonia, one of the smallest of the FSU countries with a population of 1.3 million in 2010, the average costs per patient treated for MDR-TB including XDR-TB were assessed to be US $\$ 8974$ or $€ 8530$ (US\$1 $=14.7 \mathrm{kr}$ and $€ 1=15.65 \mathrm{kr}$ ) from a health system perspective in 2003. Of note, second-line anti-TB drugs are purchased at favourable conditions for Estonia by the Global Drug Facility (GDF), established by the WHO to help low- and middle-income countries access firstand second-line drugs at the lowest possible price; thus the medication costs per MDR-TB patient were only US\$2219 in 2003 (€2084; $€ 3082$ adjusted to 2012). Most EU countries are not eligible for these prices, but new member states such as Estonia, Romania and Bulgaria are. No figures are provided for drug-susceptible TB and XDR-TB. In the analysis by FLOYD et al. [46], 192 hospital days for MDR-TB patients were included at US\$30.50 (€28.65) for the first 60 days.

However, inpatient costs per day as low as $€ 28.65$ are very unlikely to cover the up-to-date costs of 2012. For 2005, the WHO figures [51] show inpatient bed costs per day (representing the "hotel" component of hospital cost only, i.e. excluding drugs and diagnostics) for Estonia of US\$95.24, US\$124.25 and US\$169.71 for primary, secondary and tertiary levels, respectively, corresponding with $€ 76.57$, €99.90 and $€ 136.45$, respectively (according to an average exchange rate of US\$1 $=€ 0.804$ in 2005). Adjusted to 2012, hospitalisation costs in Estonia are $€ 105.59$ per day at a primary level. Therefore, we use the Estonia figure of $€ 105.59$ per hospital day at a lowest (primary) level as an average cost estimate; direct cost of treating a MDR-TB or XDR-TB patient in Estonia consequently adds up to 192 days multiplied by $€ 105.59$ (€20 273) plus medication costs of $€ 3082$, i.e. a total of $€ 23355$.

Cost estimates for susceptible TB patients are completely lacking in the new EU states. According to the European Hospital Morbidity Database [52], the average length of hospital stay due to TB varies between 28 days (Slovakia) and 91 days (Lithuania), but there is no information on which proportion of TB patients are hospitalised, and data for Estonia, Romania and Bulgaria are not assessed at all; in addition, medication costs are mentioned nowhere in the literature.

A reasonable approach to cost estimation would be to compare the gross domestic product (GDP) between EU countries; the EU-15 that were part of the EU before 2004, and Cyprus, Malta and Slovenia have a comparable GDP. The average GDP per capita in 2011 for these countries was $€ 28979$, varying between $€ 16100$ for Portugal and $€ 82000$ for Luxemburg [53]. In the nine remaining countries, on average, the GDP per capita is about a third of that, amounting to €9358 [54].

Accordingly, we estimate the total costs of treating a susceptible TB case in the new EU member states to be one-third of the mean in the old EU member states (€7848), i.e. €2616.

\section{Charging for indirect costs}

To arrive at total cost, a sum for the loss of productivity caused by TB must be added to these figures for direct treatment costs. The only precise calculation for loss of productivity due to TB in Europe was found in a study of the cost of TB in Germany by Diel et al. [41]. In this study, loss of productivity is calculated at $€ 2313$ per case (€2434 adjusted to 2012 ) regardless of drug susceptibility, since drug-resistant cases only represent $2.1 \%$ of the total number of cases and some MDR-TB patients might go to work when still undergoing treatment. As different figures are not provided by any other study, it seems reasonable to use this amount as average for all cases in countries that were part of the EU before 2004 and Cyprus, Malta and Slovenia; the latter three have GDPs closer to the EU-15 than the newer members and are usually seen as belonging to the "high-income" European countries [53].

To calculate cost of productivity loss for the nine remaining countries we considered a third of the amount we used for the 18 other EU members as shown above for direct cost, i.e. $€ 811$, to be added for each patient to the respective direct cost.

\section{Combining direct and indirect TB cost}

For the EU-18 (EU-15 plus Cyprus, Malta and Slovenia) the calculations shown earlier would result in the following total average cost of TB per case, including cost of treatment and loss of productivity: drugsusceptible cases $€ 10282$, MDR-TB $€ 57213$, and XDR-TB $€ 170744$.

The total average cost of TB in the nine remaining "new" countries then becomes: drug-susceptible cases $€ 3427, \mathrm{MDR}-\mathrm{TB} € 24166$, and XDR-TB $€ 24166$. 
Original cost data, as presented in the respective publications and the averages mentioned in the calculations earlier, were used to calculate the total cost of TB in the EU as shown in table 3. According to these calculations, the cost of TB in the EU adds up to over $€ 537$ million per year. It is conspicuous that in the "new" EU member states (as far as any assessment is possible) the cost of treating an XDR-TB case is only approximately one-seventh of that in the other EU states. This is largely due to the fact that more expensive medications such as linezolid, used to treat XDR-TB in wealthier countries, are not available at a discount and are therefore not affordable to the newer EU members. However, this does not have much influence on the total costs because of the low number of 136 XDR-TB cases notified in the whole EU. Beside the lower medication cost, the main reason for the difference is the much lower inpatient costs in those countries. Whereas the number of inpatient treatment days is comparable, e.g. 202 days in Germany and 192 days in Estonia, the inpatient cost of $€ 296.31$ per day in Germany differs substantially from the $€ 105.59$ per day in Estonia. It can be expected that in the future inpatient per-day costs, and consequently the cost of treating XDR-TB in the EU, will increase; considering the current gap between inpatient costs for TB patients and those assigned to other diseases. According to an analysis of Organisation for Economic Co-operation and Development data by FARRELL et al. [54], the average inpatient costs per day in the EU-15 states, irrespective of the type of disease, are in general much higher, varying between $€ 533$ (Germany) and $€ 1639$ (Denmark).

\section{Monetary value of DALYS}

In 2010, the most recent year for which data are available, the mean age of TB patients (notified cases) was 45.1 years, unchanged since 2001 [12]. Life expectancy in the EU-27 states, combined for both sexes, was 79.7 years [55]. Mortality in new, laboratory-confirmed pulmonary TB cases has been reported to be $6.6 \%$ as a treatment outcome and $13 \%$ for culture confirmed new MDR-TB cases after treatment duration of 24 months in the ECDC/WHO report [12]. Thus, the number of deaths due to drug-susceptible TB and MDR-TB/XDR-TB were $4642(70340 \times 0.066)$ and $211(1624 \times 0.13)$, respectively, totalling 4854 deaths (rounded) in 2012.

The calculated YLL (detailed formula are provided in the online supplementary material) were 90478.56 and the calculated total of YLD was 11592.032 (drug-susceptible TB) plus 1033.026 (MDR-/XDR-TB). Multiplication of the aggregated 103104 DALYs (rounded) by $€ 52000$ per VOLY resulted in a total of $€ 5361408000$.

\section{Discussion}

Our objective was to review and summarise the available evidence on cost and the cost components of TB and MDR-TB/XDR-TB in the EU. However, despite of a growing flood of epidemiological publications on $\mathrm{TB}$ and MDR-TB, aggregated TB costs in the individual EU member countries are sparse and information on the attributable cost components that may act as cost drivers is often incomplete.

Due to different health systems in the EU, there are considerable differences in refunding expenditures of diagnostics and treatment, and what makes the assessment of $\mathrm{TB}$ costs even more complicated methodologically is the fact that every country has its own way of monitoring and registering costs. Furthermore, the countries clearly depend on the generally differing pricing of pharmaceutical companies for identical drugs and the degree of eventual sponsoring by nonprofit organisations such as the GDF. Thus, with respect to the target cost components listed earlier, the data provided are quite heterogeneous. Indeed, there are only two studies providing weighted cost data both for drug-susceptible TB and for MDR-/XDR$\mathrm{TB}[41,44]$ in which the cost components had been comprehensively deduced from all the country-specific economic sources. For the majority of countries there were no data available at all, making extrapolation necessary.

Nevertheless, despite the limitations of our review, the best available cost data are part of the evidence needed for budgeting for and financing the expansion of TB services, especially with respect to scaling-up MDR-TB treatment. The increase of the number of cases of MDR- and XDR-TB is a real health threat but also raises an important concern about the rise of the cost of TB globally as well as in the EU. TB represents a high cost for the EU; summing nearly $€ 537$ million each year according to our conservative cost calculations and based on the ECDC/WHO Regional Office for Europe number of cases in the year 2011. Although TB rates are decreasing slightly, drug-resistant strains are on the rise, bringing an increase in treatment costs. No mention is made of MDR-TB and XDR-TB for 2011 in either Malta or Slovenia, and XDR-TB cases are reported in only 12 out of the $27 \mathrm{EU}$ countries, although we can assume that such costdriving cases were present in at least some of those countries.

We are aware that our calculations underestimate the real overall cost of TB in the EU. The study of DE VRIES et al. [44], the only one fully assessing costs due to TB cases as well as general costs, demonstrates that 


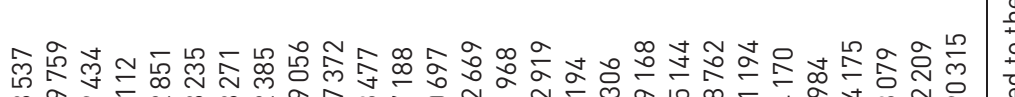

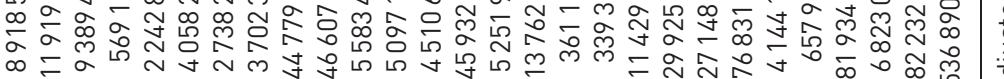

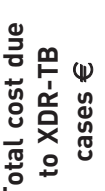

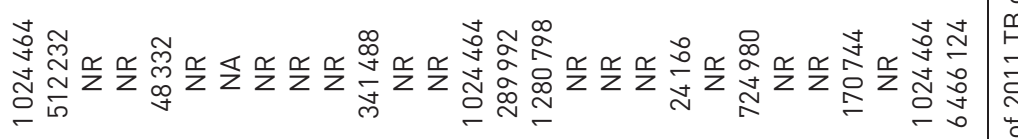
ํㅗㅁ

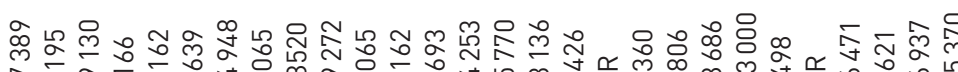

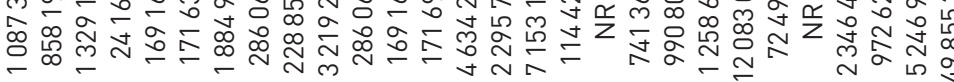

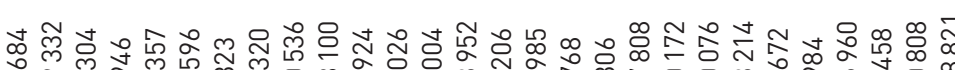

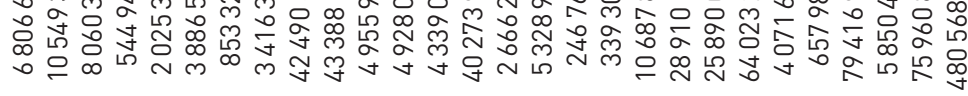

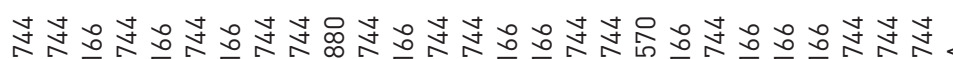

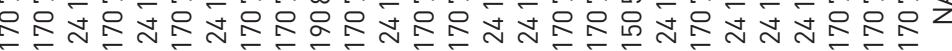

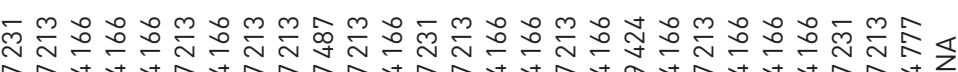

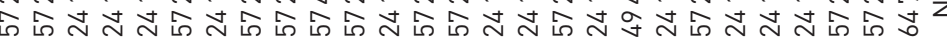

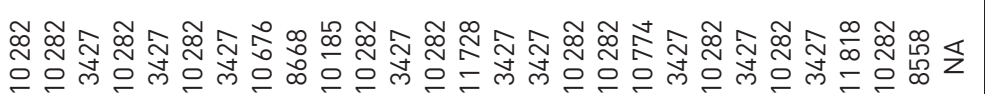

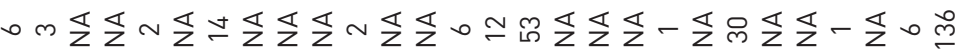

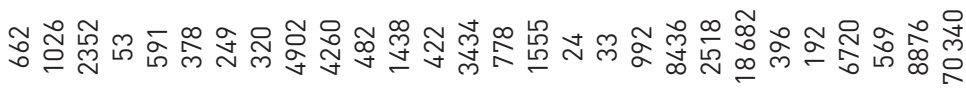


the costs due to TB of $€ 29.49$ million in 2009 in the Netherlands are mainly (61\%) due to surrounding costs such as surveillance, screening of high-risk groups, follow-up and treating of contacts and BCG vaccination. The "net" cost in the UK only for detecting and treating latent TB infection and BCG vaccination in 2006 were estimated to be GBP 10.405 million ( $€ 15.264$ million adjusted to 2012) by the calculations of the National Institute for Health and Clinical Excellence [56], indicating that costs directly linked to TB disease are meaningful but represent only a fraction of its whole financial impact.

Without new tools to control the disease, it is unlikely that the cost of TB will go down. With respect to the development of new vaccines, TBVI's funding model proposes an investment of $€ 560$ million spread over 10 years. This cost is only slightly higher than the current cost of TB disease in the EU for 1 year based on 2011 cases, but, using a minimal discount rate of 3\%, the net present value of an investment of $€ 537$ million at the end of 10 years would be $\sim € 722$ million.

Furthermore, taking into account the monetary equivalent of more than $€ 5.3$ billion for the 103104 DALYs caused by the TB cases notified in 2011, there is no doubt that the economic burden of TB provides a good rationale for investing in the development of new, safe and efficacious vaccines. In line with the new EU standards for TB care [57], such an investment could clearly contribute to fulfil the goal of eliminating TB in the future.

\section{References}

Diel R, Nienhaus A. Prevention of TB in areas of low incidence. In: Lange C, Migliori GB, eds. Tuberculosis. Eur Respir Monogr 2012; 58: 72-83.

Kaufmann SH. Fact and fiction in tuberculosis vaccine research: 10 years later. Lancet Infect Dis 2011; 11: 633-640. Brennan MJ, Stone MR, Evans T. A rational vaccine pipeline for tuberculosis. Int J Tuberc Lung Dis 2012; 16: $1566-1573$.

4 Ottenhoff TH, Kaufmann SH. Vaccines against tuberculosis: where are we and where do we need to go. PLoS Pathog 2012; 8: e1002607.

5 Parliamentary Questions: answer given by Ms Geoghegan-Quinn on behalf of the Commission. E9505/2010. www. europarl.europa.eu/sides/getAllAnswers.do?Reference=E-2010-9505\&language =FI Date last accessed: March 15, 2013. Date last updated: September 9, 2011.

6 Tuberculosis Vaccine Initiative (TBVI). Translating Science into Products through Innovative Funding A Contribution to a Healthier World and an Innovative Europe by Developing new TB vaccines. Lelystad, TBVI, 2011.

7 European Academies Science Advisory Council. Drug-Resistant Tuberculosis: Challenges, Consequences and Strategies for Control. London, EASAC, 2009.

8 Loddenkemper R, Gibson GJ, Sibille Y, eds. European Lung White Book: the First Comprehensive Survey on Respiratory Health in Europe. Sheffield, European Respiratory Society Journals, 2003.

9 van der Werf MJ, Langendam MW, Sandgren A, et al. Lack of evidence to support policy development for management of contacts of multidrug-resistant tuberculosis patients: two systematic reviews. Int J Tuberc Lung Dis 2012; 16: 288-296.

10 D’Ambrosio L, Centis R, Migliori GB. Multidrug-resistant tuberculosis. N Engl J Med 2012; 367: 2154.

11 World Health Organization. Global Tuberculosis Control 2012. Geneva, World Health Organization, 2012.

12 European Centre for Disease Prevention and Control and World Health Organization Regional Office for Europe. Surveillance Report: Tuberculosis Surveillance and Monitoring in Europe 2012. Stockholm, European Centre for Disease Prevention and Control, 2012.

13 World Health Organization. Global Tuberculosis Report 2012. Geneva, World Health Organization, 2012.

14 Skrahina A, Hurevich H, Zalutskaya A, et al. Alarming levels of drug-resistant tuberculosis in Belarus: results of a survey in Minsk. Eur Respir J 2012; 39: 1425-1431.

15 Migliori GB, Dara M, de Colombani P, et al. Multidrug-resistant tuberculosis in Eastern Europe: still on the increase? Eur Respir J 2012; 39: 1290-1291.

16 World Health Organization. Global Tuberculosis Control 2011. Geneva, World Health Organization, 2011.

17 World Health Organization Regional Office for Europe. Consolidated Action Plan to Prevent and Combat Multidrug- and Extensively Drug-Resistant Tuberculosis in the WHO European Region 2011-2015. www.euro. who.int/_data/assets/pdf_file/0007/147832/wd15E_TB_ActionPlan_111388.pdf Date last accessed: March 15, 2013. Date last updated: July 21, 2011.

18 European Centre for Disease Prevention and Control and World Health Organization Regional Office for Europe. Tuberculosis Surveillance and Monitoring in Europe 2013. Stockholm, European Centre for Disease Prevention and Control, 2013.

19 Falzon D, Gandhi N, Migliori GB, et al. Resistance to fluoroquinolones and second-line injectable drugs: impact on multidrug-resistant TB outcomes. Eur Respir J 2013; 42: 156-168.

20 Migliori GB, Sotgiu G, Gandhi NR, et al. Drug resistance beyond extensively drug-resistant tuberculosis: individual patient data meta-analysis. Eur Respir J 2013; 42: 169-179.

21 Veen J, Migliori GB, Raviglione M, et al. Harmonisation of TB control in the WHO European region: the history of the Wolfheze Workshops. Eur Respir J 2011; 37: 950-959.

22 Broekmans JF, Migliori GB, Rieder HL, et al. European framework for tuberculosis control and elimination in countries with a low incidence. Recommendations of the World Health Organization (WHO), International Union Against Tuberculosis and Lung Disease (IUATLD) and Royal Netherlands Tuberculosis Association (KNCV) Working Group. Eur Respir J 2002; 19: 765-775.

23 European Centre for Disease Prevention and Control. Progressing Towards TB Elimination. A follow-up to the Framework Action Plan to Fight Tuberculosis in the European Union. Stockholm, European Centre for Disease Prevention and Control, 2010. 
24 Diel R, Loddenkemper R, Zellweger JP, et al. Old ideas to innovate tuberculosis control: preventive treatment to achieve elimination. Eur Respir J 2013; 42: 785-801.

25 Diel R, Goletti D, Ferrara G, et al. Interferon- $\gamma$ release assays for the diagnosis of latent Mycobacterium tuberculosis infection: a systematic review and meta-analysis. Eur Respir J 2011; 37: 88-99.

26 Sester M, Sotgiu G, Lange C, et al. Interferon- $\gamma$ release assays for the diagnosis of active tuberculosis: a systematic review and meta-analysis. Eur Respir J 2011; 37: 100-111.

27 Skripconoka V, Danilovits M, Pehme L, et al. Delamanid improves outcomes and reduces mortality in multidrugresistant tuberculosis. Eur Respir J 2013; 41: 1393-1400.

28 De Lorenzo S, Alffenaar JW, Sotgiu G, et al. Efficacy and safety of meropenem-clavulanate added to linezolidcontaining regimens in the treatment of MDR-/XDR-TB. Eur Respir J 2013; 41: 1386-1392.

29 Alsaad N, van Altena R, Pranger AD, et al. Evaluation of co-trimoxazole in the treatment of multidrug-resistant tuberculosis. Eur Respir J 2013; 42: 504-512.

30 European Central Bank. Harmonised Indices of Consumer Prices, Breakdown by Purpose of Consumption. www. ecb.int/stats/prices/hicp/html/hicp_coicop_anr_2013-02.en.html Date last accessed: March 15, 2013. Date last updated: February 2013.

31 Prüss-Üstün A, Mathers C, Corvalán C, et al. Assessing the Environmental Burden of Disease at National and Local Levels. WHO Environmental Burden of Disease Series, No.1. Geneva, World Health Organization, 2003. World Health Organization. Global Burden of Disease: 2004 Update. Geneva, World Health Organisation, 2008.

33 AEA Technology Environment. Methodology Paper (Volume 2) for Service Contract for Carrying out Cost-Benefit Analysis of Air Quality Related Issues, in particular in the Clean Air for Europe (CAFE) Programme. Available from: http://cafe-cba.aeat.com/assets/volume_2_methodology_overview_02-05.pdf Oxon, AEA Technology, 2005.

34 GHK. A Study on Liability and the Health Costs of Smoking: Updated Final Report. London, GHK, 2012. Available from: http://ec.europa.eu/health/tobacco/docs/tobacco_liability_final_en.pdf.

35 White VL, Moore-Gillon J. Resource implications of patients with multidrug resistant tuberculosis. Thorax 2000; 55: 962-963.

36 Deuffic-Burban S, Atsou K, Viget N, et al. Cost-effectiveness of QuantiFERON-TB test vs. tuberculin skin test in the diagnosis of latent tuberculosis infection. Int J Tuberc Lung Dis 2010; 14: 471-481.

37 French National Assembly. Information Report. Annex No 3: Coûts comparés du traitement médicamenteux de la tuberculose en France [Cost comparison of drug treatment of tuberculosis in France]. www.assemblee-nationale.fr/ 13/rap-info/i3524.asp\#P1623_331406 Date last accessed: March 15, 2013.

38 Bocchino M, Greco S, Rosati Y, et al. Cost determinants of tuberculosis management in a low-prevalence country. Int J Tuberc Lung Dis 2006; 10: 146-152.

39 Montes-Santiago J, Fernández C, Rey G, et al. Hospitalizaciones por tuberculosis en España: análisis de sus costes [Tuberculosis-related hospitalization in Spain: a cost analysis]. Enferm Infecc Microbiol Clin 2010; 28: 358-361.

40 Rajalahti I, Ruokonen EL, Kotomäki T, et al. Economic evaluation of the use of PCR assay in diagnosing pulmonary TB in a low-incidence area. Eur Respir J 2004; 23: 446-451.

41 Diel R, Rutz S, Castell S, et al. Tuberculosis: cost of illness in Germany. Eur Respir J 2012; 40: 143-151.

42 Blaas SH, Mütterlein R, Weig J, et al. Extensively drug resistant tuberculosis in a high income country: a report of four unrelated cases. BMC Infect Dis 2008; 8: 60

43 Eker B, Ortmann J, Migliori GB, et al. Multidrug- and extensively drug-resistant tuberculosis, Germany. Emerg Infect Dis 2008; 14: 1700-1706.

44 de Vries G, Baltussen R. Kosten van tuberculose en TBC-bestrijding in Nederland [Cost of tuberculosis and tuberculosis control in the Netherlands]. Tegen Tuber 2013; 109: 3-7.

45 Rumetshofer R. Multiresistente Tuberkulose - ein Weltweites Problem [Multidrug-resistant tuberculosis - a worldwide problem]. Jatros Infektiologie 2008; 4: 20-22.

46 Floyd K, Hutubessy R, Kliiman K, et al. Cost and cost-effectiveness of multidrug-resistant tuberculosis treatment in Estonia and Russia. Eur Respir J 2012; 40: 133-142.

47 Department of Health. Supply of TB drugs to patients - changes to regulations and advice on implementation. http://webarchive.nationalarchives.gov.uk/+/www.dh.gov.uk/en/Publichealth/Communicablediseases/Tuberculosis/ DH_078136 Date last accessed: March 15, 2013. Date last updated: June 16, 2009.

48 Belgian Lung and Tuberculosis Association. BELTA TBnet Rapport, 2012. www.belta.be/content/view/71/217/ lang,french Date last accessed: March 15, 2013.

49 World Health Organization. Guidelines for the Programmatic Management of Drug-Resistant Tuberculosis, Emergency Update, 2008. Geneva, World Health Organization, 2008.

50 Falzon D, Jaramillo E, Schünemann HJ, et al. WHO guidelines for the programmatic management of drug-resistant tuberculosis: 2011 update. Eur Respir J 2011; 38: 516-528.

51 World Health Organization. Estonia. Estimates of Unit Costs for Patient Services in Estonia. www.who.int/choice/ country/est/cost/en/ Date last accessed: March 15, 2013.

52 European Hospital Morbidity Database. http://data.euro.who.int/hmdb/cbparams.php Date last accessed: March 15, 2013. Date last updated: November, 2013.

53 Eurostat European Commission. Basic Figures on the EU: Spring 2013 Edition. Brussels, European Union, 2013. Available from: http://epp.eurostat.ec.europa.eu/cache/ITY_OFFPUB/KS-GL-13-001/EN/KS-GL-13-001-EN.PDF.

54 Farrell D, Jensen E, Kocher B, et al. Accounting for the Cost of US Health Care: A New Look At Why Americans Spend More. McKinsey Global Institute, 2008. Available from: www.academyhealth.org/files/2009/monday/Jensene. pdf.

55 Eurostat. Life Expectancy at Birth, 1980-2011 (years).png. http://epp.eurostat.ec.europa.eu/statistics_explained/ index.php?title=File:Life_expectancy_at_birth,_1980-2011_\%28years\%29.png\&filetimestamp=20130129120827 Date last accessed: March 15, 2013. Date last updated: January 29, 2013.

56 National Institute for Health and Clinical Excellence. Tuberculosis: Clinical Diagnosis and Management of Tuberculosis, and Measures for its Prevention and Control. Costing Report. Implementing NICE Guidance in England. NICE clinical guideline no. 33, March 2006. Available from: www.nice.org.uk/nicemedia/pdf/ CG033CostingReport.pdf.

57 Migliori GB, Zellweger JP, Abubakar I, et al. European Union standards for tuberculosis care. Eur Respir J 2012; 39: 807-819. 